\title{
Photocatalytic Treatment of Shower Water Using a Pilot Scale Reactor
}

\author{
Yash Boyjoo, Ming Ang, and Vishnu Pareek \\ Department of Chemical Engineering, Curtin University, Perth, WA 6102, Australia \\ Correspondence should be addressed to Vishnu Pareek, v.pareek@curtin.edu.au \\ Received 27 April 2012; Revised 13 June 2012; Accepted 14 June 2012 \\ Academic Editor: Mika Sillanpää
}

Copyright () 2012 Yash Boyjoo et al. This is an open access article distributed under the Creative Commons Attribution License, which permits unrestricted use, distribution, and reproduction in any medium, provided the original work is properly cited.

Treatment of shower water deserves special consideration for reuse not only because of its low pollutant loading but also because it is produced in large quantities. In this study, a pilot scale study of photocatalytic degradation of impurities in real shower water was performed in a $31 \mathrm{~L}$ volume reactor using titanium dioxide as the photocatalyst. The reactor was operated in a continuous slurry recirculation mode. Several operational parameters were studied including the slurry initial $\mathrm{pH}$, catalyst concentration, air flow rate, and slurry recirculation rate. Up to $57 \%$ of total organic carbon (TOC) elimination was obtained after 6 hours of treatment (for 3.0 slurry initial pH, $0.07 \mathrm{gL}^{-1}$ catalyst concentration, $1.8 \mathrm{Lmin}^{-1}$ air flow rate, and $4.4 \mathrm{Lmin}^{-1}$ slurry recirculation rate). This study showed that photocatalysis could be successfully transposed from bench scale to pilot scale. Furthermore, the ease of operation and the potential to use solar energy make photocatalysis an attractive prospect with respect to treatment of grey water.

\section{Introduction}

Fresh water is getting scarcer. The number of people living in water-stressed or water-scarce countries is estimated to increase from half a billion now to three billion in 2025 [1]. Water reuse has been dubbed as the greatest challenge of the 21 st century [2], and, as such, great emphasis is being put into the development of new technologies for the treatment of wastewater for reuse.

Since the discovery, in 1977, that titanium dioxide $\left(\mathrm{TiO}_{2}\right)$ could decompose cyanide in water [3], the field of photocatalysis has been receiving increasing interest. Photocatalysis is an advanced oxidation process (AOP) that uses a catalyst (often $\mathrm{TiO}_{2}$ ), UV light, and an electron acceptor $\left(\mathrm{O}_{2}, \mathrm{O}_{3}, \mathrm{H}_{2} \mathrm{O}_{2}\right)$ to completely decompose organic pollutants found in liquids or gases. The basis of the process is the use of low energy UV-A photons (for which the energy is greater or equal to the band gap energy of the catalyst) to excite the semiconductor catalyst into charge separation and generate electron-hole pairs. The electrons and holes, on separation, assist in the production of the very reactive hydroxyl radical in the aqueous phase which can destroy many toxic organic pollutants. This technology however works best at low pollutant concentrations $\left(\mathrm{mgL}^{-1}\right.$ or $\mathrm{mmolL}^{-1}$ ) and when the catalyst is finely dispersed within the medium. The overall process can be described by the following reaction equation:

$$
\begin{aligned}
& \text { organic pollutants }+\mathrm{O}_{2} \\
& \stackrel{\text { semiconductor + UVA light }}{\longrightarrow} \mathrm{CO}_{2}+\mathrm{H}_{2} \mathrm{O}+\text { mineral acid. }
\end{aligned}
$$

Shower water is part of grey water and is produced by every household at a substantial amount (15-55 $\mathrm{L} \mathrm{day}^{-1}$ ) with a pollutant loading up to $100 \mathrm{mgL}^{-1}$ [4]. Existing technologies for the treatment of grey water include membrane filtration, coagulation, ion exchange, and membrane bioreactors [5, 6]. However these techniques are either costly or merely transfer the pollutants from one medium to another. As a result, shower water is a good candidate for photocatalytic treatment. The treated water could be reused where potable water is not required. Such applications include toilet flushing, landscape irrigation, and car washing.

Countless researches have been made on the photocatalytic treatment of single or a few organic components in water [7-9]. Real wastewaters on the other hand have a 
TABLE 1: Shower water characterization.

\begin{tabular}{ll}
\hline TOC $\left(\mathrm{mgL}^{-1}\right)$ & $24.62 \pm 0.44$ \\
$\mathrm{pH}$ & $7.37 \pm 0.14$ \\
& $\begin{array}{l}\text { Anionic surfactants (sodium laureth } \\
\text { sulphate, sodium cocoamphoacetate, } \\
\text { sodium lauryl sulphate, ammonium }\end{array}$ \\
Main constituents (as per & $\begin{array}{l}\text { laureth sulphate), cationic surfactants } \\
\text { (cocamide MEA), nonionic } \\
\text { the products' ingredients } \\
\text { list) }\end{array}$ \\
& $\begin{array}{l}\text { surfactants (lauryl glucoside, cetyl } \\
\text { alcohol), fragrance, antimicrobial } \\
\text { agents. }\end{array}$ \\
\hline
\end{tabular}

multitude of pollutants and take longer to treat (typically a few hours) [10-14].

The photooxidation of surfactants, the main components of shower water, was extensively studied by Hidaka and coworkers [15-19]. They found that photodegradation decreases in the following order: anionic $>$ nonionic $>$ cationic surfactants, and postulated that photocatalysis was mainly a surface reaction due to the short lifetime of hydroxyl radicals. Sanchez et al. [20] successfully obtained 65\% dissolved organic carbon (DOC) removal with hotel grey water at $29 \mathrm{mgL}^{-1}$ initial DOC concentration while Zhu et al. found [21] that photocatalysis can effectively remove carbonaceous and nitrogenous biochemical oxygen demand from synthetic grey waters. Photocatalysis has also been reported to be efficient in the disinfection of E-coli [22], a microorganism bound to be present in wastewater that had had contact with humans. The vast majority of photocatalytic research has been performed at bench scale. If it is desired to commercialise this technique, pilot scale experiments are required so as to obtain a better understanding of the operational and hydrodynamic factors involved with higher throughputs.

The objective of this research was to study pollutant degradation in shower water in a pilot scale photocatalytic reactor ( $31 \mathrm{~L}$ volume) operating in a recirculation mode. The effect of several parameters such as the initial slurry $\mathrm{pH}$, air flow rate, slurry recirculation rate, and catalyst dosage was studied. All experiments were carried out for a period of 6 hours, which was deemed a reasonable treatment time.

\section{Experimental}

2.1. Shower Water Characterisation. Shower water was collected daily from the researcher's home and stocked in the laboratory prior to the experiments. The same cleaning products were used each time (shampoo, face wash, and body soap) to maintain consistency. The characteristics of the collected shower water are presented in Table 1.

The TOC level of the shower water suggests that it is a low strength grey water. The main constituents of liquid soaps and shampoos are surfactants which can add up to $80 \%$ by weight of chemicals content [23]. Some other constituents that may be present in trace amounts in the shower water include sebum, microorganisms, and dyes.
2.2. Reagents and Analytical Methods. Aeroxide P25 titanium dioxide was purchased from Sigma Aldrich and was used as received. The catalyst had the following properties: $21 \mathrm{~nm}$ particle size, $50 \pm 15 \mathrm{~m}^{2} \mathrm{~g}^{-1}$ BET specific surface area, $>99.5 \% \mathrm{TiO}_{2}$ content [24], and a band gap energy of $3.2 \mathrm{eV}$, corresponding to photons with wavelengths less or equal to $385 \mathrm{~nm}$ [25]. A $6 \mathrm{M}$ hydrochloric acid was used to modify the slurry $\mathrm{pH}$ prior to reaction. Compressed air was used as feed gas to the reactor and for UV lamp cooling. Tap water was used to dilute the shower water (if required). Slurry $\mathrm{pH}$ was measured with a TPS digital $\mathrm{pH}$ meter, which was calibrated periodically. Samples collected were filtered with 0.45 microns syringe filters and analysed for total organic carbon (TOC) on a Shimadzu TOC-V $\mathrm{V}_{\mathrm{CPH} / \mathrm{CPN}}$ analyser (Shimadzu Corporation, Japan).

2.3. Reactor Setup. Figure 1 shows the reactor setup used in this study. The reactor volume was $31 \mathrm{~L}(30 \mathrm{~cm}$ diameter) and was operated in recirculation mode. Ambient air was supplied by a compressor via a $10 \mathrm{~cm}$ distributor centred at the bottom of the reactor. Part of the compressed air was also used as coolant for the UV lamp. The UV mercury lamp, purchased from Primarc Ltd. (PM 3426, $800 \mathrm{~W}, 20 \mathrm{~cm}$ length medium pressure mercury lamp), was fitted into a quartz tube and suspended in the middle of the reactor. A digital thermocouple provided the temperature within the reactor. The temperature was maintained between 26 and $28^{\circ} \mathrm{C}$ by varying the rate of cooling water which ran through a coiled heat exchanger located around walls at the bottom of the reactor. An Iwaki magnetic pump was used for slurry circulation. Slurry flow rate was varied using valve V2 while air flow rate was varied via valve V5.

2.4. Procedure. Shower water was diluted with tap water (if required) and mixed with the titanium dioxide powder in a $60 \mathrm{~L}$ tank. The $\mathrm{pH}$ was adjusted, and the slurry was allowed to mix for 30 minutes to allow for dark adsorption of pollutants onto the catalyst surface. Compressed air as well as cooling water was started, and the slurry was transferred to the reactor via the Iwaki magnetic pump. Once the reactor was filled, valve V1 was closed, valve V3 was opened to allow the reactor to operate in recirculation mode, and, finally, the lamp was switched on. Samples were taken in $20 \mathrm{~mL}$ aliquots via sample valve V6 and were filtered prior to analysis.

\section{Results and Discussion}

Since the shower water consisted of a myriad of organic components, a realistic way of reporting the pollutant concentration was by measuring the total organic carbon (TOC in $\mathrm{mgL}^{-1}$ ) of the samples. The average reaction rate for TOC elimination was calculated using the following equation:

$$
-R_{\mathrm{TOC}}=\frac{\mathrm{TOC}_{\text {initial }}-\mathrm{TOC}_{\text {final }}}{\tau}
$$

where $-R_{\text {TOC }}$ is the average rate of degradation of TOC $\left(\mathrm{molL}^{-1} \mathrm{~min}^{-1}\right), \mathrm{TOC}_{\text {initial }}$ and $\mathrm{TOC}_{\mathrm{final}}$ are the initial and 


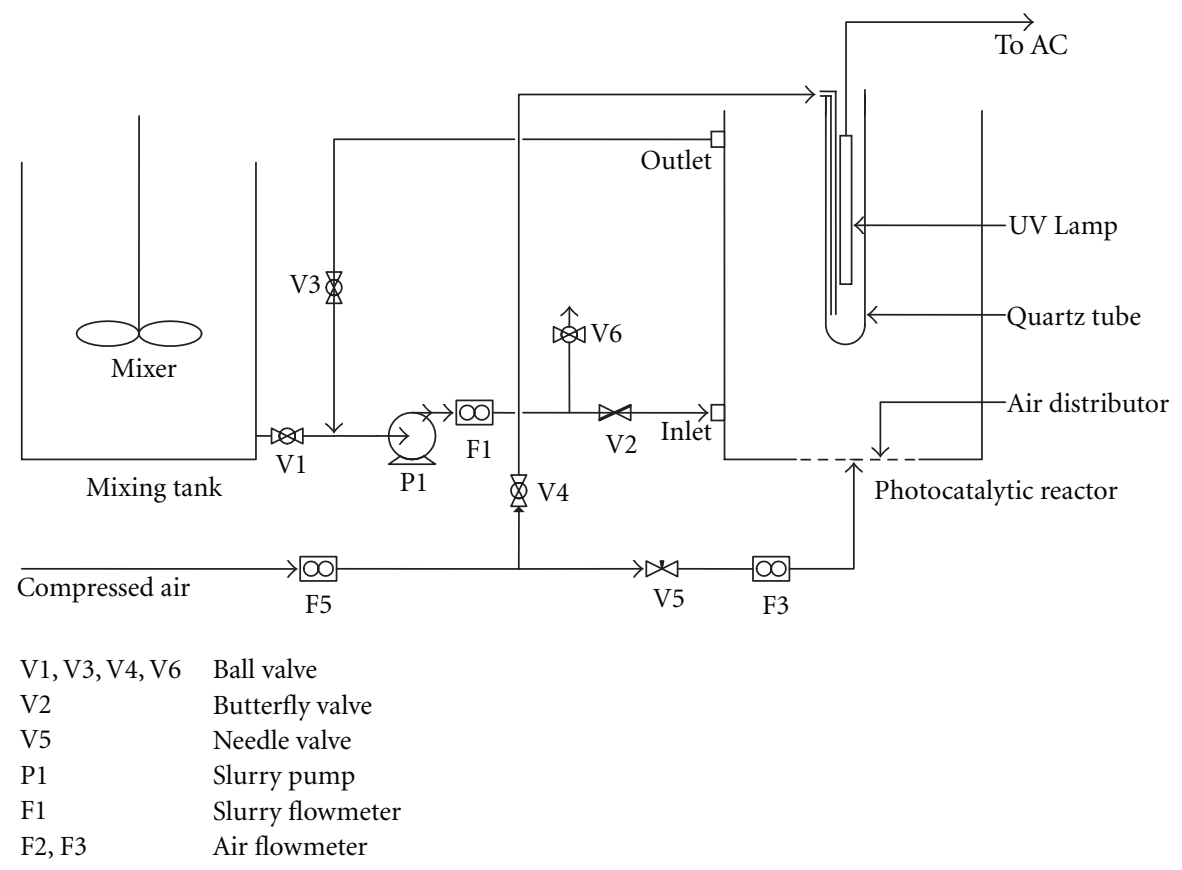

FIGURE 1: Experimental setup for photocatalysis experiments. Shower water was mixed for 30 minutes with catalyst and acid in mixing tank initially before mixture was sent to the photocatalytic reactor via pump P1. Reactor was operated in recirculation mode.

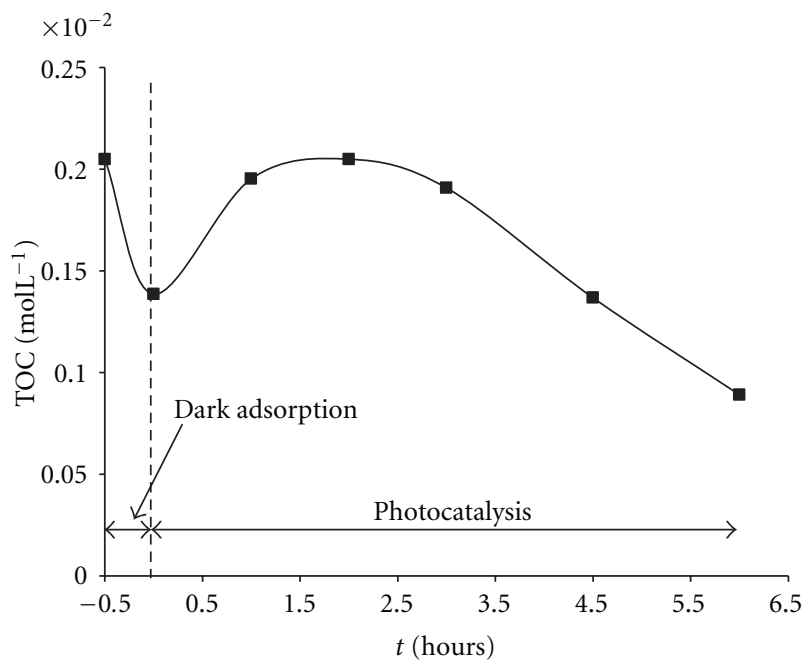

Figure 2: Temporal course for shower water photocatalysis at optimum conditions (TOC initial concentration $=24.62 \pm$ $0.44 \mathrm{mgL}^{-1}$, average reaction temperature $=27^{\circ} \mathrm{C}$, initial slurry $\mathrm{pH}=3.00,0.07 \mathrm{gL}^{-1}$ catalyst loading, $1.8 \mathrm{Lmin}^{-1}$ air flow rate and 4.4 $\mathrm{Lmin}^{-1}$ slurry flow rate).

final TOC concentration $\left(\mathrm{molL}^{-1}\right)$, and $\tau$ is the real contact time (minutes) in the reactor which is 360 minutes.

3.1. Photocatalysis of Shower Water. The temporal course at optimum conditions for the photocatalysis of shower water in terms of TOC reduction is illustrated in Figure 2. Part of the TOC was adsorbed onto the catalyst surface during the dark adsorption stage. Upon irradiation, the
TOC concentration increased to a maximum within the first two hours of reaction that corresponded to the initial TOC concentration prior to dark adsorption. This phenomenon had been observed previously $[17,26,27]$ for the photocatalytic oxidation of anionic surfactants at low initial concentrations. The initial increase in TOC can be attributed to the formation of intermediates on the catalyst surface followed by photodesorption of the intermediates back into the liquid medium. Several types of intermediates are formed via the photooxidation of long chained hydrocarbons. Zhang et al. [27] reported the formation of aldehyde and peroxide intermediates during the photooxidation of surfactants.

A reduction in the TOC concentration was then observed after 2 hours due to the onset of oxidation of organic pollutants. This reduction was only moderate from $t=2 \mathrm{~h}$ to $t=3 \mathrm{~h}$ probably due to a large quantity of long chained organics/intermediates still remaining in the solution. However, as the photoreaction proceeded, the long chained organics/intermediates cleaved into smaller chained intermediates for which mineralisation to carbon dioxide, water, and mineral acids took place at a faster rate, as observed after $t=3 \mathrm{~h}$. A maximum of $57 \%$ TOC degradation was obtained within 6 hours of treatment at optimum conditions.

3.2. Effect of Slurry Initial $p H$. The initial $\mathrm{pH}$ of the slurry is an important parameter that needs to be considered as it influences the surface charge properties of the catalyst particles [9], hence the adsorption of charged pollutants. Figure 3 shows the effect of the slurry initial $\mathrm{pH}$ on the average rate of TOC degradation. There was a gradual increase in the average reaction rate as the $\mathrm{pH}$ was decreased from 7.4 (natural $\mathrm{pH}$ ) to 5.0. The increase in reaction rate 


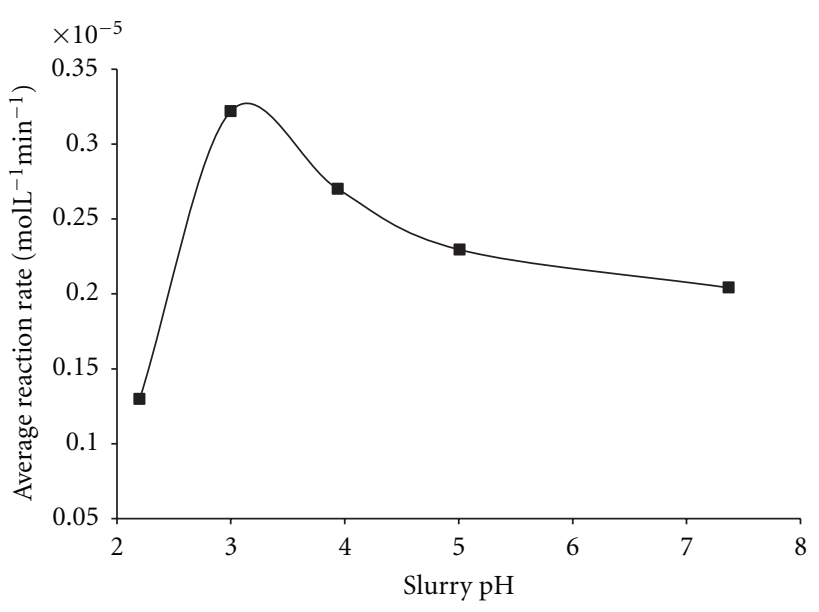

FIGURE 3: Effect of slurry initial $\mathrm{pH}$ on average reaction rate (TOC initial concentration $=24.62 \pm 0.44 \mathrm{mgL}^{-1}$, average reaction temperature $=27^{\circ} \mathrm{C}, 0.07 \mathrm{gL}^{-1}$ catalyst loading, $1.8 \mathrm{Lmin}^{-1}$ air flow rate and $4.4 \mathrm{Lmin}^{-1}$ slurry flow rate).

became steeper as the $\mathrm{pH}$ was further lowered and reached a maximum at $\mathrm{pH}=3.0$. Further lowering of the $\mathrm{pH}$ to 2.2 led to a sharp decrease in the reaction rate.

Titanium dioxide is amphoteric by nature which means that past a certain $\mathrm{pH}$, it can be either positively or negatively charged. That $\mathrm{pH}$, which is called the point of zero charge (ZPC), occurs at a value of 6.5 for Aeroxide P25 titanium dioxide [28]. Hence when $\mathrm{pH}<\mathrm{ZPC}$, the $\mathrm{TiO}_{2}$ is positively charged while at $\mathrm{pH}>\mathrm{ZPC}$, it is negatively charged as shown as follows:

$$
\begin{gathered}
\text { when } \mathrm{pH}<\mathrm{ZPC} \text { : } \mathrm{TiOH}+\mathrm{H}^{+} \longleftrightarrow \mathrm{TiOH}_{2}^{+} \text {, } \\
\text { when } \mathrm{pH}>\mathrm{ZPC} \text { : } \mathrm{TiOH}+\mathrm{OH}^{-} \longleftrightarrow \mathrm{TiO}^{-}+\mathrm{H}_{2} \mathrm{O} .
\end{gathered}
$$

This implies that at lower $\mathrm{pH}$, the positively charged $\mathrm{TiO}_{2}$ surface can easily attract the negatively charged species from the solution, hence facilitating their photooxidation. The main components of the shower water used were anionic surfactants as presented in Table 1 . As the $\mathrm{pH}$ of the slurry was decreased, the positive surface charge of the $\mathrm{TiO}_{2}$ increased, attracting more and more anionic groups to its surface. This is further evident with the change in the dark adsorption with slurry $\mathrm{pH}$ in Figure 4, which shows that pollutant species during the dark adsorption remained constant between $\mathrm{pH}$ of 7.4 and 5.0 but then increased sharply to reach a maximum of $32.4 \%$ adsorption at $\mathrm{pH}$ 3.0. Another research involving anionic surfactants has also shown preferential photooxidation at low $\mathrm{pH}[29,30]$.

Being radical scavengers, carbonate anions present in the wastewater can inhibit photooxidation [31]. However an acidic medium can remove these unwanted anions as per the following equations:

$$
\begin{aligned}
& \mathrm{HCO}_{3}^{-}+\mathrm{H}^{+} \longrightarrow \mathrm{H}_{2} \mathrm{O}+\mathrm{CO}_{2}, \\
& \mathrm{CO}_{3}^{2-}+2 \mathrm{H}^{+} \longrightarrow \mathrm{H}_{2} \mathrm{O}+\mathrm{CO}_{2} .
\end{aligned}
$$

Nonetheless, Figure 3 shows that a further reduction of $\mathrm{pH}$ to 2.2 was in fact detrimental to the degradation of TOC. This

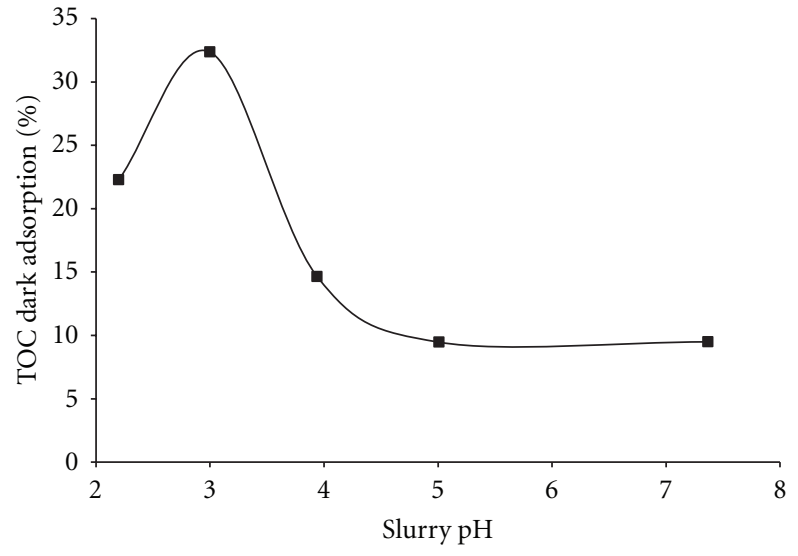

FIGURE 4: Effect of slurry initial $\mathrm{pH}$ on amount of TOC adsorbed in the dark.

was attributed to high levels of $\mathrm{Cl}^{-}$ions in the solution. $\mathrm{Cl}^{-}$ ions are scavengers of hydroxyl radicals as well as holes [32] and can therefore greatly reduce the photooxidation process. As the $\mathrm{pH}$ was decreased from 3.0 to 2.2 , the concentration of $\mathrm{Cl}^{-}$increased exponentially from $1 \times 10^{-3} \mathrm{M}$ to $6.3 \times 10^{-3} \mathrm{M}$, hence explaining the rapid decrease in the TOC removal rate. The optimum $\mathrm{pH}$ of 3.0 was maintained throughout subsequent experiments.

3.3. Effect of Catalyst Dosage. Most wastewater photocatalytic treatment studies report an optimum catalyst concentration. Beyond that optimum, the rate of reaction either remains unchanged or decreases. Figure 5 shows the effect of catalyst loading on the average reaction rate with the range of catalyst loading investigated between 0.03 and $0.15 \mathrm{gL}^{-1}$. It is clear that the optimum catalyst concentration was about $0.07 \mathrm{gL}^{-1}$.

Reported optimum catalyst loadings for wastewater treatment are usually within a range of $0.1-1 \mathrm{gL}^{-1}[7,8,33]$; however some studies have also reported lower optimum loadings $\left(0.05 \mathrm{gL}^{-1}\right)$ [34]. However, in all cases, the optimum value strongly depends on the reactor design, pollutant type, and concentration [35].

In the current study, a relatively low value of optimum catalyst loading could be attributed to low concentrations of shower water as well as the large reactor diameter. Lower catalyst loadings provided sufficient sites for photoreaction and allowed a maximum possible illumination of the reaction space. Beyond those loadings, the decrease in average reaction rate was probably due to the backscattering of light by the catalyst particles, entailing a shielding effect on the remaining reaction space. Simulation studies are currently being carried out to verify these hypotheses.

The effect of catalyst concentration, $W_{\text {cat }}\left(g_{\text {cat }} \mathrm{L}^{-1}\right)$, on the average reaction rate, $-R_{\mathrm{TOC}}\left(\mathrm{molL}^{-1} \mathrm{~min}^{-1}\right)$, could be described as:

$$
-R_{\mathrm{TOC}}=A+\frac{B}{\left(W_{\mathrm{cat}}-C\right)^{2}+D},
$$




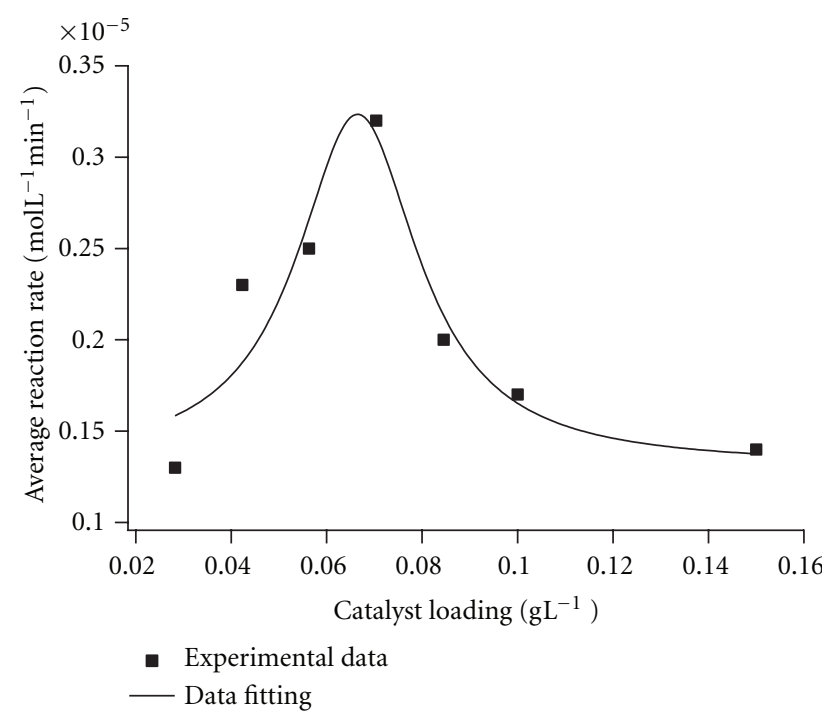

FIGURE 5: Effect of catalyst loading on average reaction rate (TOC initial concentration $=24.62 \pm 0.44 \mathrm{mgL}^{-1}$, average reaction temperature $=27^{\circ} \mathrm{C}$, initial slurry $\mathrm{pH}=3.00,1.8 \mathrm{Lmin}^{-1}$ air flow rate and $4.4 \mathrm{Lmin}^{-1}$ slurry flow rate).

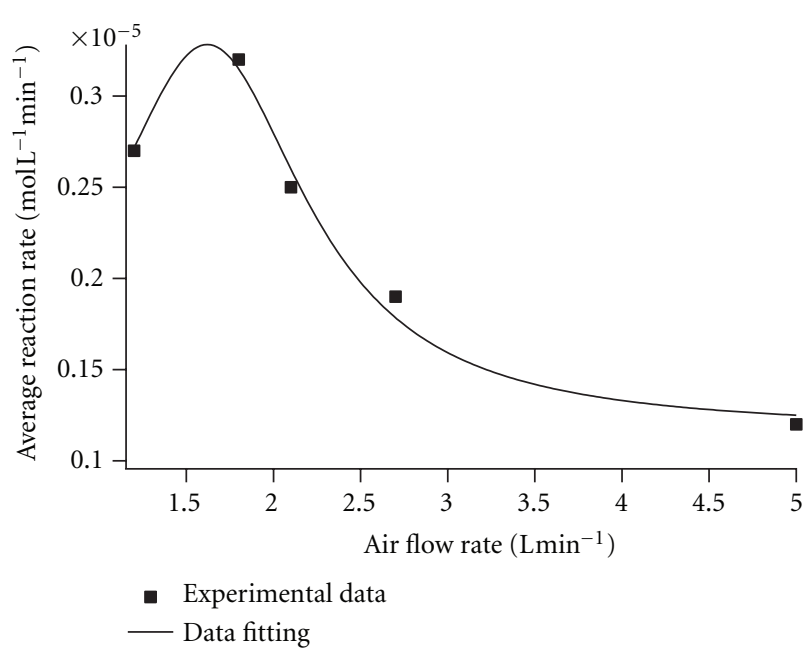

Figure 6: Effect of air flow rate on average reaction rate (TOC initial concentration $=24.62 \pm 0.44 \mathrm{mgL}^{-1}$, average reaction temperature $=27^{\circ} \mathrm{C}$, initial slurry $\mathrm{pH}=3.00,0.07 \mathrm{gL}^{-1}$ catalyst loading and $4.4 \mathrm{Lmin}^{-1}$ slurry flow rate).

where the values for $A, B, C$, and $D$ are $1.31 \times 10^{-6}$ $\mathrm{molL}^{-1} \mathrm{~min}^{-1}, 4.66 \times 10^{-10} g_{\mathrm{cat}}{ }^{2} \mathrm{molL}^{-3} \mathrm{~min}^{-1}, 6.64 \times 10^{-2}$ $g_{\text {cat }} \mathrm{L}^{-1}$, and $2.42 \times 10^{-4} g_{\text {cat }}{ }^{2} \mathrm{~L}^{-2}$, respectively.

3.4. Effect of Air Flow Rate. Upon irradiation, the catalyst particles generate positive holes and electrons. The photooxidation process requires an oxidising agent to remove electrons from the catalyst surface and prevent them from recombining with positive holes which are responsible for the creation of hydroxyl radicals. In this study, the oxidant was oxygen in the air.

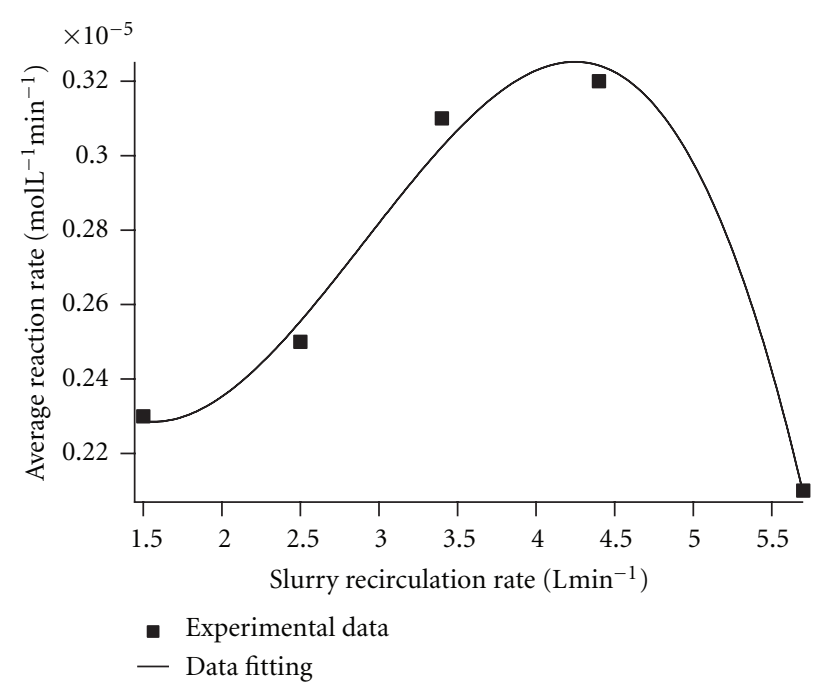

FIGURE 7: Effect of slurry recirculation rate on average reaction rate (TOC initial concentration $=24.62 \pm 0.44 \mathrm{mgL}^{-1}$, average reaction temperature $=27^{\circ} \mathrm{C}$, initial slurry $\mathrm{pH}=3.00,0.07 \mathrm{gL}^{-1}$ catalyst loading and $1.8 \mathrm{Lmin}^{-1}$ air flow rate).

The range of air flow rate investigated was between 1.5 and $5.0 \mathrm{Lmin}^{-1}$ as depicted in Figure 6. The average TOC degradation rate was found to increase until an optimum was reached at $1.8 \mathrm{Lmin}^{-1}$ air flow rate after which a steep decrease in the reaction rate was observed. Visual observations showed that fine bubbles were formed at the lower air flow rates. However, beyond the optimum air flow rate, larger bubbles of widespread sizes were observed. Larger bubbles meant reduced surface area for mass transfer of oxygen from the gas to liquid phase, hence the reduction in the average reaction rate. Agustina et al. [36] made a similar observation in their study of winery wastewater treatment with the same reactor. On the other hand, at low air flow rates in the vicinity of $1.5 \mathrm{Lmin}^{-1}$, air bubbles had a tendency to penetrate the slurry outlet, leading to irregular liquid pumping, hence a reduced average reaction rate.

The effect of air flow rate, $Q_{\text {Air }}\left(\mathrm{Lmin}^{-1}\right)$, on the average reaction rate, $-R_{\mathrm{TOC}}\left(\mathrm{molL}^{-1} \mathrm{~min}^{-1}\right)$, could be described as

$$
-R_{\mathrm{TOC}}=A+\frac{B}{\left(Q_{\mathrm{Air}}-C\right)^{2}+D},
$$

where the values for $A, B, C$, and $D$ are $7.06 \times 10^{-5}$ $\mathrm{molL}^{-1} \mathrm{~min}^{-1}, 5.93 \times 10^{-5} \mathrm{molLmin}^{-3}, 1.62 \mathrm{Lmin}^{-1}$, and $0.47 \mathrm{~L}^{2} \mathrm{~min}^{-2}$, respectively.

3.5. Effect of Slurry Recirculation Rate. The recirculation rate of the slurry was varied to study the effect of the residence time. The circulation rate was varied between 1.5 and $5.7 \mathrm{Lmin}^{-1}$, and its effect on the average reaction rate is presented in Figure 7. Maximum degradation was obtained at a recirculation rate of $4.4 \mathrm{Lmin}^{-1}$. At higher recirculation rate, the slurry inlet momentum was high enough that air bubbles had the tendency to be pushed towards the slurry outlet. Introducing air bubbles into the pipelines made pumping irregular and therefore reduced the average 
TABLE 2: Breakdown of electrical cost for 1 run of photocatalytic shower water treatment at optimum conditions.

\begin{tabular}{lccccc}
\hline Equipment & Power rating $(\mathrm{kW})$ & Power usage $(\%)$ & Usage $(\mathrm{h})$ & Energy usage $(\mathrm{kWh})$ & Cost @ 0.35 US\$kWh $^{-1}\left(\mathrm{USSm}^{-3}\right)$ \\
\hline Pump & 0.135 & 70 & 6 & 0.57 & 6.5 \\
UV lamp & 0.8 & 80 & 6 & 3.84 & 42.9 \\
\hline Total & & & 4.41 & 49.4 \\
\hline
\end{tabular}

reaction rate. Pareek et al. [37] found maximum degradation at a recirculation rate of $0.2 \mathrm{Lmin}^{-1}$ in an $18 \mathrm{~L}$ volume reactor for the photodegradation of Bayer liquor. However in their study, catalyst suspension was assisted by fine air bubbles homogeneously distributed within the reactor. In this study, air bubbles were supplied from a $10 \mathrm{~cm}$ distributor centred at the bottom of the reactor. These bubbles were not dispersed throughout the reactor space, and, as a result, a relatively high volumetric flow rate was necessary to suspend the catalyst particles.

The effect of slurry recirculation rate, $Q_{\text {slurry }}\left(\mathrm{Lmin}^{-1}\right)$, on the average reaction rate, $-R_{\mathrm{TOC}}\left(\mathrm{molL}^{-1} \mathrm{~min}^{-1}\right)$, could be described as

$$
-R_{\mathrm{TOC}}=k_{0}+k_{1} Q_{\text {Slurry }}+k_{2} Q_{\text {Slurry }}{ }^{2}+k_{3} Q_{\text {Slurry }}{ }^{3} .
$$

The values of $k_{0}, k_{1}, k_{2}$, and $k_{3}$ are $3.66 \times 10^{-6} \mathrm{molL}^{-1} \mathrm{~min}^{-1}$, $-2.00 \times 10^{-6} \mathrm{molL}^{-2}, 8.75 \times 10^{-7} \mathrm{molminL}^{-3}$, and $-1.00 \times$ $10^{-7} \operatorname{molmin}^{2} \mathrm{~L}^{-4}$, respectively.

3.6. Electricity Cost Analysis. Based on the current electricity cost in Perth, Australia (0.35 US\$ $\mathrm{kWh}^{-1}$ ), a cost analysis was performed as detailed in Table 2 .

Therefore for a $31 \mathrm{~L}$ throughput, the treatment cost

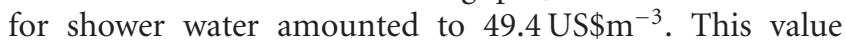
was close to the price range obtained by Pareek et al. [37] (60-270 US $\left.\$ \mathrm{~m}^{-3}\right)$ for the photocatalytic treatment of industrial Bayer liquor but is much larger than the reported 3.75 Euros $\cdot \mathrm{m}^{-3}$ for the photocatalytic treatment of herbicides [38] most probably due to the size (bench scale) of the latter research. However, it is possible to operate the reactor with solar light; it is envisaged that operational cost of a large-scale photoreactor for shower water purification will be much less.

\section{Conclusions}

A pilot scale study for the photocatalytic degradation of real shower water showed that photocatalysis can be an efficient treatment process. At optimum conditions (3.0 slurry initial $\mathrm{pH}, \quad 0.07 \mathrm{gL}^{-1}$ catalyst concentration, $4.4 \mathrm{Lmin}^{-1}$ slurry recirculation rate, and $1.8 \mathrm{Lmin}^{-1}$ air supply), a $57 \%$ of TOC degradation was obtained after 6-hour treatment time, although higher TOC degradation is expected if the treatment time is increased. This study showed that photocatalysis could be successfully transposed from bench scale to pilot scale. Furthermore, the ease of operation of the process makes photocatalysis an attractive prospect in terms of grey water treatment.

\section{References}

[1] A. Stikker, "Water today and tomorrow: prospects for overcoming scarcity," Futures, vol. 30, no. 1, pp. 43-62, 1998.

[2] T. Asano, "Water from (waste)water-the dependable water resource," Water Science and Technology, vol. 45, no. 8, pp. 2433, 2002.

[3] A. Fujishima and X. Zhang, "Titanium dioxide photocatalysis: present situation and future approaches," Comptes Rendus Chimie, vol. 9, no. 5-6, pp. 750-760, 2006.

[4] E. Eriksson, K. Auffarth, M. Henze, and A. Ledin, "Characteristics of grey wastewater," Urban Water, vol. 4, no. 1, pp. 85-104, 2002.

[5] F. Li, K. Wichmann, and R. Otterpohl, "Review of the technological approaches for grey water treatment and reuses," Science of the Total Environment, vol. 407, no. 11, pp. 34393449, 2009.

[6] B. Jefferson, A. Laine, S. Parsons, T. Stephenson, and S. Judd, "Technologies for domestic wastewater recycling," Urban Water, vol. 1, no. 4, pp. 285-292, 2000.

[7] V. Belgiorno, L. Rizzo, D. Fatta et al., "Review on endocrine disrupting-emerging compounds in urban wastewater: occurrence and removal by photocatalysis and ultrasonic irradiation for wastewater reuse," Desalination, vol. 215, no. 1-3, pp. 166176, 2007.

[8] M. Pera-Titus, V. García-Molina, M. A. Baños, J. Giménez, and S. Esplugas, "Degradation of chlorophenols by means of advanced oxidation processes: a general review," Applied Catalysis B, vol. 47, no. 4, pp. 219-256, 2004.

[9] U. I. Gaya and A. H. Abdullah, "Heterogeneous photocatalytic degradation of organic contaminants over titanium dioxide: a review of fundamentals, progress and problems," Journal of Photochemistry and Photobiology C, vol. 9, no. 1, pp. 1-12, 2008.

[10] I. A. Balcioglu and I. Arslan, "Application of photocatalytic oxidation treatment to pretreated and raw effluents from the Kraft bleaching process and textile industry," Environmental Pollution, vol. 103, no. 2-3, pp. 261-268, 1998.

[11] A. C. Rodrigues, M. Boroski, N. S. Shimada, J. C. Garcia, J. Nozaki, and N. Hioka, "Treatment of paper pulp and paper mill wastewater by coagulation-flocculation followed by heterogeneous photocatalysis," Journal of Photochemistry and Photobiology A, vol. 194, no. 1, pp. 1-10, 2008.

[12] P. A. Pekakis, N. P. Xekoukoulotakis, and D. Mantzavinos, "Treatment of textile dyehouse wastewater by $\mathrm{TiO}_{2}$ photocatalysis," Water Research, vol. 40, no. 6, pp. 1276-1286, 2006.

[13] H. El Hajjouji, F. Barje, E. Pinelli et al., "Photochemical $\mathrm{UV} / \mathrm{TiO}_{2}$ treatment of olive mill wastewater (OMW)," Bioresource Technology, vol. 99, no. 15, pp. 7264-7269, 2008.

[14] C. Fotiadis, N. P. Xekoukoulotakis, and D. Mantzavinos, "Photocatalytic treatment of wastewater from cottonseed processing: effect of operating conditions, aerobic biodegradability and ecotoxicity," Catalysis Today, vol. 124, no. 3-4, pp. 247-253, 2007. 
[15] H. Hidaka, H. Kubota, M. Graätzel, E. Pelizzetti, and N. Serpone, "Photodegradation of surfactants II: degradation of sodium dodecylbenzene sulphonate catalysed by titanium dioxide particles," Journal of Photochemistry, vol. 35, no. 2, pp. 219-230, 1986.

[16] H. Hidaka, K. Ihara, Y. Fujita, S. Yamada, E. Pelizzetti, and N. Serpone, "Photodegradation of surfactants IV: photodegradation of non-ionic surfactants in aqueous titanium dioxide suspensions," Journal of Photochemistry and Photobiology A, vol. 42, no. 2-3, pp. 375-381, 1988.

[17] H. Hidaka, T. Oyama, T. Horiuchi, T. Koike, and N. Serpone, "Photo-induced oxidative synergistic degradation of mixed anionic/cationic surfactant systems in aqueous dispersions. A detailed study of the DBS/HTAB system," Applied Catalysis B, vol. 99, no. 3-4, pp. 485-489, 2010.

[18] H. Hidaka and J. Zhao, "Photodegradation of surfactants catalyzed by a $\mathrm{TiO}_{2}$ semiconductor," Colloids and Surfaces, vol. 67, pp. 165-182, 1992.

[19] J. Zhao, H. Oota, H. Hidaka, E. Pelizzetti, and N. Serpone, "Photodegradation of surfactants X. Comparison of the photo-oxidation of the aromatic moieties in sodium dodecylbenzene sulphonate and in sodium phenyldodecyl sulphonate at $\mathrm{TiO}_{2} \mathrm{H}_{2} \mathrm{O}$ interfaces," Journal of Photochemistry and Photobiology A, vol. 69, no. 2, pp. 251-256, 1992.

[20] M. Sanchez, M. J. Rivero, and I. Ortiz, "Photocatalytic oxidation of grey water over titanium dioxide suspensions," Desalination, vol. 262, no. 1-3, pp. 141-146, 2010.

[21] X. Zhu, M. A. Nanny, and E. C. Butler, "Photocatalytic oxidation of aqueous ammonia in model gray waters," Water Research, vol. 42, no. 10-11, pp. 2736-2744, 2008.

[22] R. van Grieken, J. Marugán, C. Sordo, and C. Pablos, "Comparison of the photocatalytic disinfection of E. coli suspensions in slurry, wall and fixed-bed reactors," Catalysis Today, vol. 144, no. 1-2, pp. 48-54, 2009.

[23] K. Y. Lai, Liquid Detergents, Taylor \& Francis, 2005.

[24] Inorganic materials for catalyst innovation, "AEROSIL, AEROXIDE and SIPERNAT metal oxides and silica based materials industry information 2242," Evonik Industries, 2011.

[25] M. I. Cabrera, O. M. Alfano, and A. E. Cassano, "Absorption and scattering coefficients of titanium dioxide participate suspensions in water," Journal of Physical Chemistry, vol. 100, no. 51, pp. 20043-20050, 1996.

[26] Y. Y. Eng, V. K. Sharma, and A. K. Ray, "Photocatalytic degradation of nonionic surfactant, Brij 35 in aqueous $\mathrm{TiO}_{2}$ suspensions," Chemosphere, vol. 79, no. 2, pp. 205-209, 2010.

[27] R. Zhang, L. Gao, and Q. Zhang, "Photodegradation of surfactants on the nanosized $\mathrm{TiO}_{2}$ prepared by hydrolysis of the alkoxide titanium," Chemosphere, vol. 54, no. 3, pp. 405$411,2004$.

[28] J. R. Regalbuto, Catalyst Preparation: Science and Engineering, CRC Press/Taylor \& Francis, 2007.

[29] T. Oyama, A. Aoshima, S. Horikoshi, H. Hidaka, J. Zhao, and N. Serpone, "Solar photocatalysis, photodegradation of a commercial detergent in aqueous $\mathrm{TiO}_{2}$ dispersions under sunlight irradiation," Solar Energy, vol. 77, no. 5, pp. 525-532, 2004.

[30] M. Sanchez, M. J. Rivero, and I. Ortiz, "Kinetics of dodecylbenzenesulphonate mineralisation by $\mathrm{TiO}_{2}$ photocatalysis," Applied Catalysis B, vol. 101, no. 3-4, pp. 515-521, 2011.

[31] R. Andreozzi, V. Caprio, A. Insola, and R. Marotta, "Advanced oxidation processes (AOP) for water purification and recovery," Catalysis Today, vol. 53, no. 1, pp. 51-59, 1999.
[32] M. N. Chong, B. Jin, C. W. K. Chow, and C. Saint, "Recent developments in photocatalytic water treatment technology: a review," Water Research, vol. 44, no. 10, pp. 2997-3027, 2010.

[33] J. Lea and A. A. Adesina, "The photo-oxidative degradation of sodium dodecyl sulphate in aerated aqueous $\mathrm{TiO}_{2}$ suspension," Journal of Photochemistry and Photobiology A, vol. 118, no. 2, pp. 111-122, 1998.

[34] A. E. H. Machado, J. A. de Miranda, R. F. de Freitas et al., "Destruction of the organic matter present in effluent from a cellulose and paper industry using photocatalysis," Journal of Photochemistry and Photobiology A, vol. 155, no. 1-3, pp. 231241, 2003.

[35] P. R. Gogate and A. B. Pandit, "A review of imperative technologies for wastewater treatment I: oxidation technologies at ambient conditions," Advances in Environmental Research, vol. 8, no. 3-4, pp. 501-551, 2004.

[36] T. E. Agustina, H. M. Ang, and V. K. Pareek, "Treatment of winery wastewater using a photocatalytic/photolytic reactor," Chemical Engineering Journal, vol. 135, no. 1-2, pp. 151-156, 2008.

[37] V. K. Pareek, M. P. Brungs, and A. A. Adesina, "Continuous process for photodegradation of industrial bayer liquor," Industrial and Engineering Chemistry Research, vol. 40, no. 23, pp. 5120-5125, 2001.

[38] G. Li Puma, B. Toepfer, and A. Gora, "Photocatalytic oxidation of multicomponent systems of herbicides: scale-up of laboratory kinetics rate data to plant scale," Catalysis Today, vol. 124, no. 3-4, pp. 124-132, 2007. 


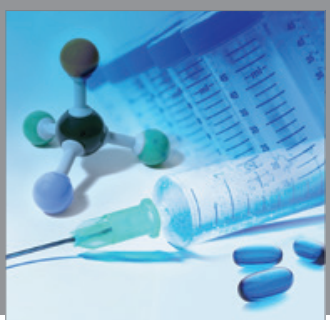

International Journal of

Medicinal Chemistry

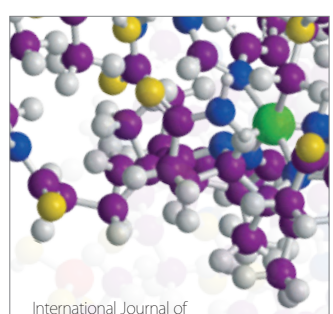

Carbohydrate Chemistry

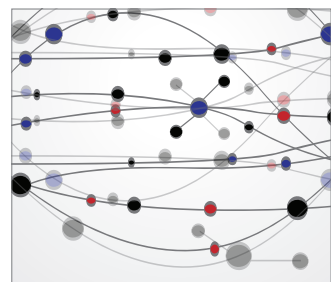

The Scientific World Journal
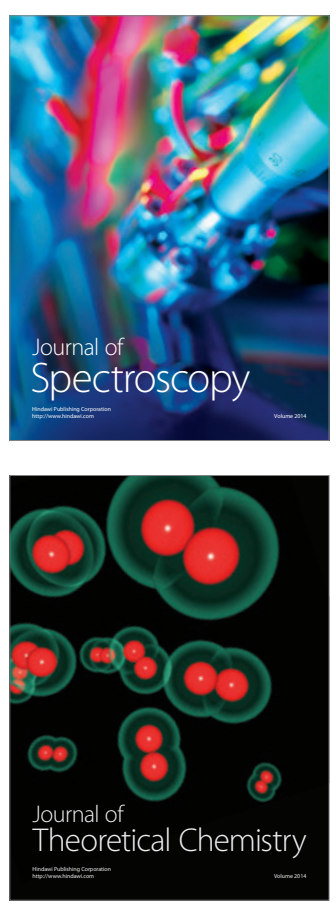
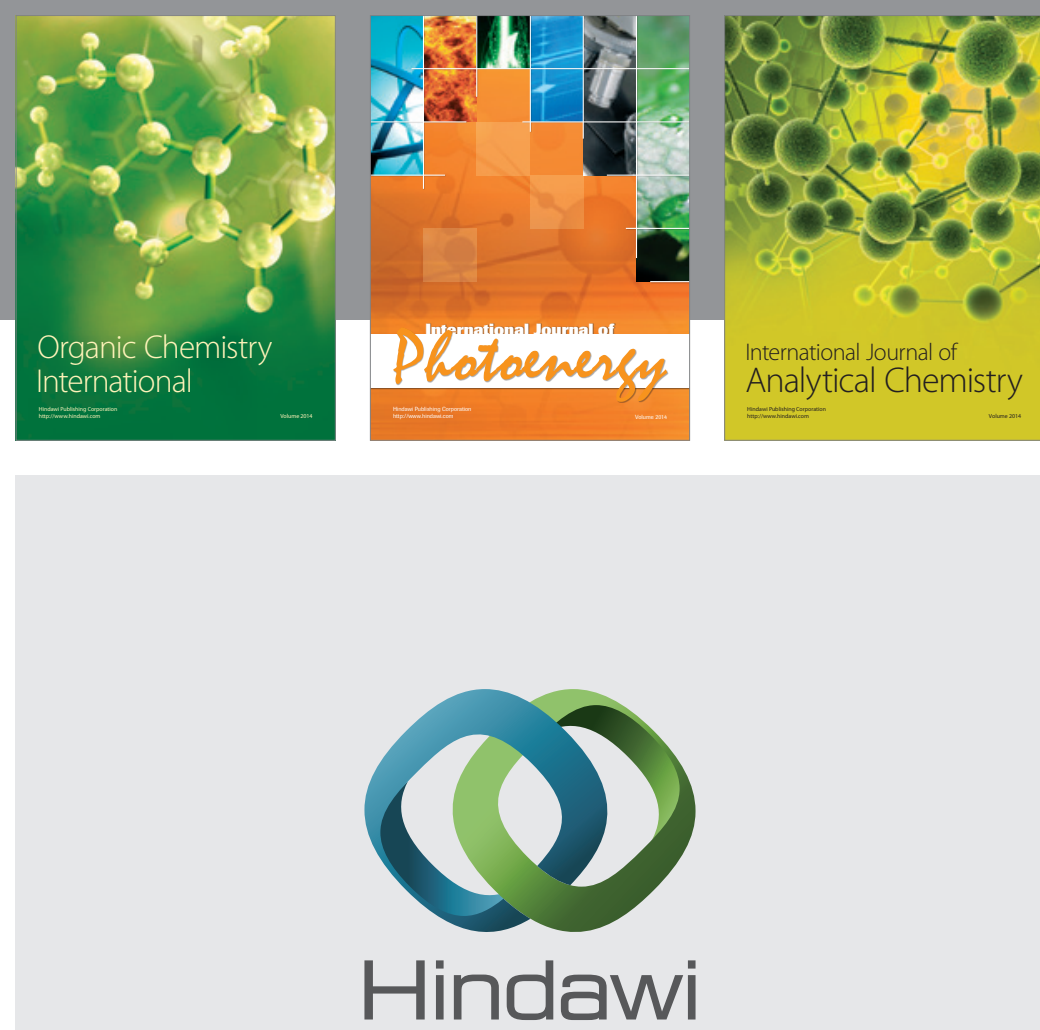

Submit your manuscripts at

http://www.hindawi.com
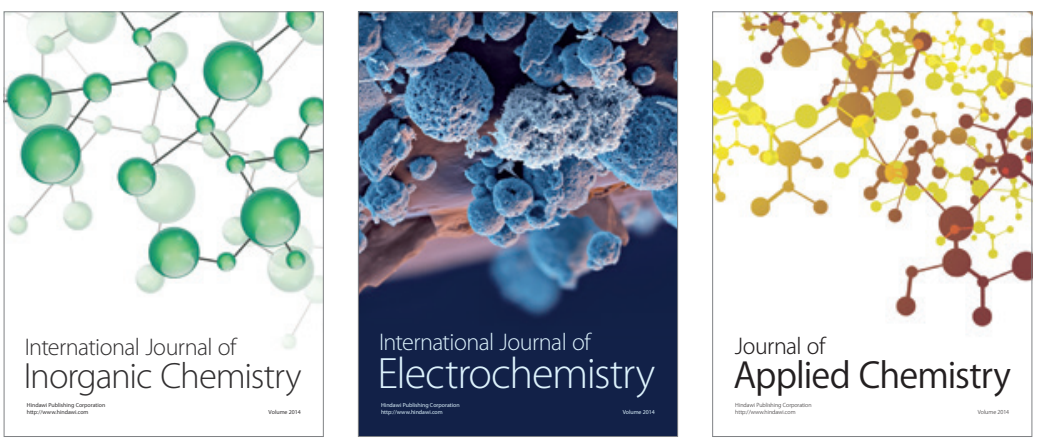

Journal of

Applied Chemistry
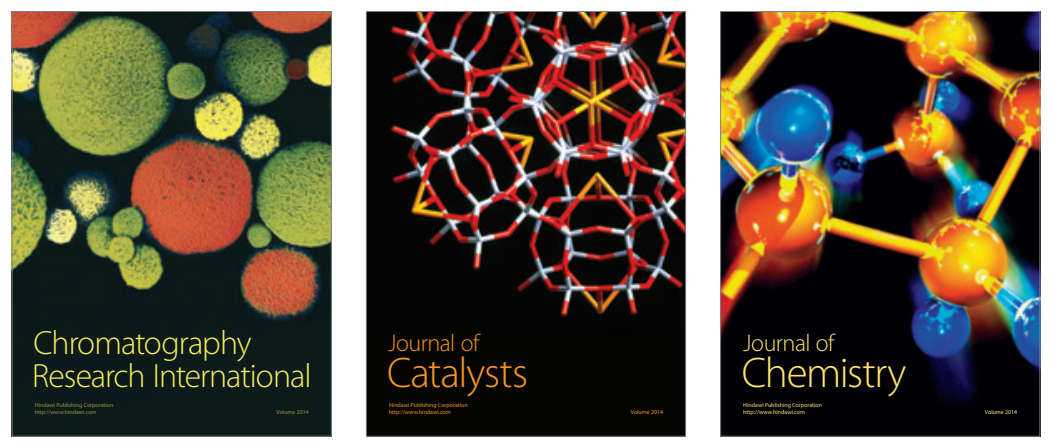
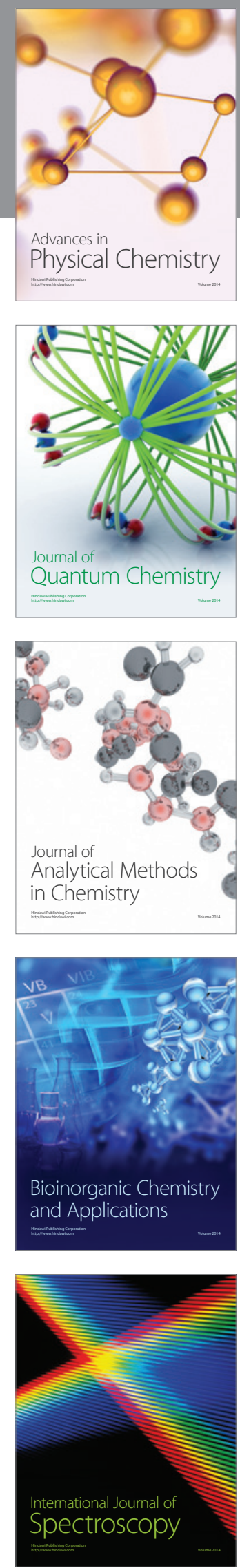